\title{
ELEMENTOS SIMBÓLICOS DE LA CONSTITUCIÓN ESPAÑOLA. LA PROTECCIÓN DEL USO DE LOS SÍMBOLOS POR LAS PERSONAS Y LAS INSTITUCIONES
}

\section{Symbolic elements of the Spanish Constitution. Protection of the use of symbols by citizens and institutions}

\author{
ENRIQUE BELDA \\ Universidad de Castilla-La Mancha \\ Enrique.Belda@uclm.es
}

Cómo citar/Citation

Belda, E. (2019)

Elementos simbólicos de la Constitución española. La protección

del uso de los símbolos por las personas y las instituciones.

Revista Española de Derecho Constitucional, 117, 45-75

doi: https://doi.org/10.18042/cepc/redc.117.02

\section{Resumen}

Los símbolos del Estado no pueden considerarse por el derecho desde una perspectiva defensiva y reactiva, provocada por el enfrentamiento sentimental en la sociedad. Su utilización o cuestionamiento es la consecuencia del ejercicio de libertades y derechos fundamentales, y es en ese ámbito donde el operador jurídico ha de constatar su pertinente uso o eventual menoscabo. La protección de los símbolos tiene un componente de respeto a ideas, patrias, e instituciones, pero comprende también el amparo de su uso por cada ciudadano como medio para el ejercicio de sus derechos. Las reformas legislativas encaminadas a la protección de los símbolos deberían ser puestas en relación con los derechos fundamentales que se descubren tras su uso o tras su crítica, y las consecuencias jurídicas deben ser ponderadas adecuadamente.

\section{Palabras clave}

Símbolo; bandera; Corona; libertad de expresión; libertad de pensamiento; libertad ideológica; pluralismo político. 


\begin{abstract}
The symbols of the State cannot be considered by law from a defensive and reactive perspective, caused by the sentimental confrontation of many societies. Their use or questioning is the consequence of the exercise of freedom and fundamental rights, and it is in this area, where the legal operator has to verify the symbols pertinent use or eventual impairment. The protection of symbols stems from the respect for ideas, homelands, and institutions, but should also include the protection of their use by each citizen as a means to exercise their rights and freedom. Legislative reforms aimed at the protection of symbols should be put in relation to the fundamental rights that are discovered after their use or after their criticism, and the legal consequences must be adequately weighed.
\end{abstract}

\title{
Keywords
}

Symbol; flag; Crown; freedom of expression; freedom of thought; ideological freedom; political pluralism. 


\section{SUMARIO}

I. EXPOSICIÓN DEL PROBLEMA, OBJETIVOS, Y DELIMITACIÓN DE LOS SÍMBOLOS CON RELEVANCIA CONSTITUCIONAL: 1. El problema. 2. Los objetivos del análisis. 3. Los símbolos constitucionales. II. LA PROTECCIÓN JURÍDICA DE LOS SÍMBOLOS DEL ESTADO Y LAS CONSECUENCIAS DE SU MENOSCABO: 1. Protección constitucional de la simbología. 2. Protección constitucional del uso de la simbología. 3. Concreción normativa y jurisprudencial de la protección del símbolo y de su uso: la respuesta ante los ataques al objeto y a la materialización de los derechos mediante la exhibición: 3.1. Reacción ante el menoscabo de banderas o de la Corona como símbolo. 3.2. Reacción ante las trabas al uso de la simbología para la expresión personal y la canalización del ejercicio de otros derechos. III. LA NECESIDAD DE RESPALDAR LOS SÍMBOLOS EN SENTIDO ESTRICTO CON ARGUMENTOS CONSTITUCIONALES DE PESO. IV. LA CONVIVENCIA DE LA COBERTURA DEL USO CIUDADANO DE LOS SÍMBOLOS, CON SU PROTECCIÓN COMO OBJETOS SIN AFECTAR DERECHOS Y LIBERTADES. V. EL USO DE LOS SÍMBOLOS POR LOS RESPONSABLES INSTITUCIONALES. DE LA AFRENTA A LOS SÍMBOLOS CONSTITUCIONALES A LA PROMOCIÓN DE SIMBOLOGÍA ALTERNATIVA. REMISIÓN. BIBLIOGRAFÍA.

\section{EXPOSICIÓN DEL PROBLEMA, OBJETIVOS, Y DELIMITACIÓN DE LOS SÍMBOLOS CON RELEVANCIA CONSTITUCIONAL}

\section{EL PROBLEMA}

La España de los últimos años conoce, entre sus variados retos, dos situaciones de cuestionamiento constitucional de evidente carga política, pero también sentimental (motivo por el cual la simbología alcanza notoriedad en el análisis): el deseo de parte de las sociedades de algunas comunidades autónomas de independizarse del Estado español, y el aumento de los apoyos ciudadanos a minorías antisistema, o, cuando menos, cuestionadoras del régimen constitucional de 1978 y de la forma de su jefatura del Estado. Ambos movimientos, al margen de las aportaciones políticas o jurídicas que inserten en el debate social, manejan cotidianamente elementos sentimentales en cuya exposición pública adquiere la simbología su protagonismo: banderas, himnos y emblemas de cualquier naturaleza. Ante esta situación, también el resto de la ciudadanía acompaña en la expresión de su acuerdo o desacuerdo con las ideas de los colectivos independentistas o revisionistas del sistema con la utilización de símbolos (especialmente las banderas constitucionales) con una frecuencia mayor que en 
décadas pasadas. En este ambiente, se produce un manejo simbólico habitualmente normalizado (adecuado a las finalidades que los mismos asumen en nuestras sociedades), aunque de manera excepcional también el símbolo sea objeto de transgresión, con el objetivo de refrendar una expresión pública de rechazo hacia lo que representa. En estas circunstancias (p. ej., quema de banderas, inversión o destrucción de la imagen del monarca constitucional), la ciudadanía y los operadores jurídicos se preguntan sobre el régimen de uso de la simbología nacional, su "contrauso» o crítica, y los límites de la misma. A ese problema de expresión por parte de las personas se une otro no menos trascendente, como es el respeto de los símbolos por los responsables de los poderes públicos. En algunas nacionalidades y corporaciones locales no solo se ignoran las obligaciones legales derivadas del reconocimiento y protección oficial en torno a la exhibición y exposición de los símbolos constitucionales, sino que se promueve la utilización de otros alternativos a los legalmente establecidos, en detrimento de estos últimos.

\section{LOS OBJETIVOS DEL ANÁLISIS}

En el presente estudio, conforme puede comprobarse en el sumario, se quieren delimitar los símbolos objeto de protección constitucional, y tras ello analizar la respuesta del sistema ante los ataques a los que se exponen, para ofrecer una salida articuladora del problema basada en la presencia de los derechos y libertades como clave de la interpretación y la respuesta del Estado a la protección de sus símbolos, huyendo con ello de cualesquiera planteamientos que penalicen jurídicamente a quien solo transgrede el símbolo, pero no los derechos ajenos.

\section{LOS SÍMBOLOS CONSTITUCIONALES}

Los símbolos en sentido estricto que recoge la Constitución española de 1978 son dos: la bandera (mejor dicho, las banderas), del art. $4 \mathrm{CE}^{1}$, y la Corona, en el modo expresado por el art. $56.1 \mathrm{CE}^{2}$, interpretado de acuerdo

1 Art. 4. 1 CE: «La bandera de España está formada por tres franjas horizontales, roja, amarilla y roja, siendo la amarilla de doble anchura que cada una de las rojas. 2. Los Estatutos podrán reconocer banderas y enseñas propias de las Comunidades Autónomas. Estas se utilizarán junto a la bandera de Espańa en sus edificios públicos y en sus actos oficiales".

2 Art. 56. 1 CE: «El Rey es el Jefe del Estado, símbolo de su unidad y permanencia, arbitra y modera el funcionamiento regular de las instituciones, asume la más alta 
con las exigencias del art. 1.3 CE y del título II CE, muy en particular desde el art. $64 \mathrm{CE}$. El Estado tiene otros símbolos, como los himnos nacionales y autonómicos o los escudos, regulados convenientemente en otras normas ${ }^{3}$, a los que extenderemos las consideraciones que aquí se efectúen respecto de los símbolos expresamente constitucionalizados. Se trata únicamente de argumentar en la presente aportación sobre los márgenes de relación que van a surgir con los derechos en una interpretación intraconstitucional, con lo cual es secundario recordar el sometimiento que se proyectará sobre otros símbolos de estatuto legal, puestos también en concordancia con el respeto a los derechos constitucionalizados. Himnos, escudos, divisas, etc., son claros símbolos del Estado, solo que la Constitución de 1978, a diferencia de la Constitución francesa ${ }^{4}$, no les ha conferido una garantía constitucional similar a la de las banderas, a las que se refiere en solitario, como ocurre con el art. 12 de la Constitución italiana, pero añadiendo semejante protección a las enseñas territoriales que se determinen. Alemania, con el art. 22.2 de la Ley Fundamental de Bonn, solo se refiere a la bandera federal, no a otros símbolos, y deja la referencia a las banderas de sus estados a las respectivas constituciones de sus territorios. En la Constitución española de 1931 se hizo también una escueta mención a los colores de la bandera, pero solo la de toda la República, a diferencia del reconocimiento expreso actual de las banderas de regiones y nacionalidades (Solozábal, 2008: 76). La mención actual es escueta pero importante, dada la destacada posición en el art. cuarto, muy al comienzo de la Ley de Leyes (Troncoso, 2018: 31) .

representación del Estado español en las relaciones internacionales, especialmente con las naciones de su comunidad histórica, y ejerce las funciones que le atribuyen expresamente la Constitución y las leyes». Entre lo más reciente del rey como símbolo, Rollnert, 2019a: 11-36. Algunos autores subrayan que, en realidad, toda la actividad del rey es meramente simbólica (Belda, 2015).

3 Ley 33/1981, de 5 de octubre, del Escudo de España, y Real Decreto 1560/1997, de 10 de octubre, por el que se regula el Himno Nacional; Estatutos de Autonomía y normas de desarrollo, como la Ley 3/1982, de 21 de diciembre, sobre el himno y escudo de Andalucía, y textos normativos similares de País Vasco, Castilla-La Mancha y Madrid (1983), Comunidad Valenciana, Galicia y Principado de Asturias (1984), Extremadura (1985), Cantabria (1987), Aragón (1989), Cataluña (1993), Canarias (2003), Baleares (2015) o Navarra (2017).

4 Constituciones como la francesa incluyen, además de la bandera, su himno, su lema y su divisa (art. 2, Constitución francesa de 1958).

5 Antecedentes de elaboración del art. 4 de la Constitución, precedentes de constitucionalismo histórico e influencias en el mismo del derecho comparado se encuentran en estudios generalistas conocidos (por todos, Alzaga, 2016: 93). 
La mayor parte de consideraciones sobre la bandera van a ser extensibles al resto de los símbolos, aunque el régimen jurídico de protección del escudo o el himno sea infraconstitucional. No deja de ser reseñable cómo pasa casi inadvertida doctrinalmente la diferencia de estatuto normativo cuando se formulan conclusiones al respecto y se incluye en un mismo paquete de análisis himno, escudo y bandera. La realidad es que la Carta Magna de 1978 presenta dos símbolos con una protección directa, la bandera nacional y la Corona; otros con similar atención pero pendientes de desarrollo estatutario (las banderas de las comunidades autónomas), y omite una llamada o reserva normativa para cualesquiera otros símbolos, sin perjuicio de que el legislador pueda llegar a conferirles una protección específica, pero que no podrá equipararse formalmente a la constitucional, que es de primera magnitud.

Eludimos el tratamiento de figuras mencionadas constitucionalmente con fuerte carga simbólica, que en realidad alcanzan un estatuto muy superior por primar en ellas rasgos medulares de la construcción constitucional y ser objeto de protección y consideración más consagrada (los valores superiores del art. 1.1 CE, la dignidad del art. 10.1 CE), así como de referencias institucionales y territoriales que algunos autores entienden como simbólicas (la capitalidad del Estado) ${ }^{6}$, pero cuyo primer objetivo en la Constitución, a diferencia de lo que ocurre con la bandera y la Corona, no es simbolizar. En efecto, todo es símbolo, algunas figuras marcadamente, como nos recuerda Häberle, pero no siempre exclusiva o primariamente. Finalmente, por tener que limitar el objeto de estudio a los parámetros de extensión solicitados por la editora de esta publicación, es necesario eludir cualquier referencia a la amplísima cuestión del respeto hacia los símbolos y manifestaciones externas de las confesiones religiosas, campo donde hasta el momento más actividad de

6 Troncoso, 2018: 58: «[...] no es en puridad un símbolo, aunque también tiene un importante contenido simbólico». Lo cierto es que cada institución y cada derecho puede asumir esa condición, especialmente aquellas figuras distinguibles en las dignified parts de la Constitución (frente a otras exentas de esa proyección, en las efficient parts (Brage, 2008: 33, con cita a Bagehot), por lo que preferimos ceñirnos a las figuras constitucionalmente diseñadas para funcionar específicamente como símbolos.

7 Häberle (2012: 95-114) expone el encuadramiento que ha de realizarse de los símbolos nacionales: banderas, escudos, himnos, fiestas nacionales, capitalidad o cualesquiera otros que se perciban así, como elementos de identidad cultural de su Estado constitucional. Esta teoría la viene difundiendo desde anteriores obras (Häberle, 1987). 
interpretación del derecho se ha generado, pero que no se presenta como esencial en un estudio de esta figura concreta que nos trata, que es la simbología de un país o Estado. Ni que decir tiene que en la Constitución todo puede tener una lectura simbólica, incluida la propia Carta Magna en sí misma ${ }^{8}$, cada derecho, o cada prescripción normativa9.

Ya expuesto todo lo anterior, anuncio que en las siguientes líneas no solo se trata de aportar ideas para reforzar el amparo de los símbolos objetivos: pretendemos también dar por sentada la protección «instrumental» de los símbolos, sin duda más importante. Es decir, la necesaria cobertura del uso de los mismos por las personas, para materializar algunos de sus derechos y libertades.

\section{LA PROTECCIÓN JURÍDICA DE LOS SÍMBOLOS DEL ESTADO Y LAS CONSECUENCIAS DE SU MENOSCABO}

\section{PROTECCIÓN CONSTITUCIONAL DE LA SIMBOLOGÍA}

La posición constitucional de las banderas y de la Corona puede informar de la importancia que se les quiso conferir en su día, al mencionar las primeras al comienzo de la redacción constitucional, y la segundo en el frontispicio de la parte orgánica, aunque ambas cosas puedan ser solo fruto del mantenimiento de un orden metodológico parecido, en prescripciones históricas similares. La trascendencia jurídica viene de la mano de su respectiva inclusión en dos títulos, el Preliminar y el Segundo, dotados de una especial fortaleza o resistencia ante la reforma, según el art. $168 \mathrm{CE}$, y que da lugar a una protección que ha sido calificada como reforzada (Solozábal, 2008: 78) ${ }^{10}$. Las banderas han recibido

8 Tajadura, 2001: 32. Tanto la Constitución como sus fórmulas concretas tienen carácter de símbolos jurídicos en cuanto que se expresan hacia la vida diaria de la ciudadanía y de los operadores jurídicos. Tajadura señala los preámbulos constitucionales como lugares idóneos para demostrar la simbología en ese sentido. Tajadura (ibid: 33): «La idoneidad del texto preambular para suscitar esta identificación hace de él un factor de integración material de primer orden». Sobre la naturaleza simbólica de la Constitución, véase también Mendizábal, 2000.

9 P. ej., la prestación de juramento o promesa de lealtad a la Constitución (Gutiérrez, 2018: 1951-1969). A pesar de lo que simboliza para el que lo emplea, como ocurre con la exclusión del presente estudio de la exteriorización de credos, nos referiremos aquí a una simbología político-administrativa identitaria, y no a la que refleja opciones espirituales de los optantes a cargos y funciones constitucionales o públicas.

10 Trata las banderas en este estudio. Tal protección deriva de una necesidad en el contexto histórico de la Transición (Solozábal, 2008: 77). 
atención complementaria del legislador en aquello que no se deduce de la declaración del art. $4 \mathrm{CE}$, mientras que la Corona asume un completo estatuto entre los arts. 56 a $65 \mathrm{CE}$, que, al menos para consolidar su faceta o naturaleza simbólica, no requiere de intervenciones posteriores.

Así, la Constitución protege la figura de la bandera nacional, en las siguientes vertientes: 1) su composición, delimitando forma y colores (art. 4.1 CE), y 2) su utilización en edificios públicos y actos oficiales de las comunidades autónomas (art. 4.2 in fine). Y ampara las banderas de las comunidades autónomas: 1) configurando para ellas una reserva de creación y regulación a través de los respectivos estatutos de autonomía (art. 4.2), y 2) ordenando su uso junto a la bandera común de España en sus edificios y actos públicos (art. 4.2 in fine).

Esta es la protección de rango constitucional de la que tenemos que partir de cara a una lectura contrastada de la Ley de Leyes, frente a eventuales preceptos de los que se derive cualquier cobertura ante menosprecios o presuntas afrentas de estos símbolos. Es una configuración que ampara lo sustancial (la elección de los colores de la enseña —cuestión trascendente en ambientes históricos de discusión sobre lo que reflejan los mismos - ${ }^{11}$ y la exigencia de su uso). Asimismo, denota un destacado interés del constituyente por exaltar el simbolismo de los territorios que componen Espańa, puesto que les confiere la potestad de elegir banderas en su ámbito de decisión a través de la reserva estatutaria, pero iguala la exigencia de uso al mismo nivel y condiciones con las que ampara la bandera común. La constitucionalización de esta igualdad en el uso, en la exhibición, es de marcada importancia para analizar el compromiso con las identidades históricas y socioculturales de un Estado descentralizado ${ }^{12}$. Es al respecto reseñable, más allá de la anécdota, que se ampare a nivel constitucional, aunque sea indirectamente para proteger las enseñas autonómicas, a la bandera de España, cuando se trata de que ondee en edificios y actos de las comunidades autónomas, mientras que la protección de esta bandera común en edificios y actos del Estado recibe solo la cobertura de rango legal que le confiere el art. 3 de la Ley 39/1981, de 28 de octubre, reguladora de su uso.

11 Brage (2008: 31) apunta algunas causas de la desafección simbólica en España respecto de bandera e himno nacionales.

12 En el trabajo de Solozábal de 2008, el autor acude, cuando se trata de subrayar el significado del reconocimiento de las banderas autonómicas, al contenido de la STC 94/1985, de 29 de julio, decisión que a su juicio engrandece el papel del art. 4.2 CE sobre la constitucionalización de las banderas autonómicas: no tiene precedentes en derecho histórico ni en el constitucionalismo europeo cercano. 
Formando parte del núcleo configurador, pero desde normas de rango inferior a la Constitución, los estatutos de autonomía establecen las respectivas enseñas. La Ley 39/1981, de 28 de octubre, por la que se regula el uso de la bandera de España y el de otras banderas, así como las normas autonómicas en desarrollo de cada prescripción estatutaria ${ }^{13}$, ańade aspectos de relevancia práctica aportando elementos de distinta naturaleza en los que priman las instrucciones de uso. La norma estatal de desarrollo, Ley 39/1981, de 28 de octubre, opta por dar contenido a lo que el símbolo representa: la nación, la soberanía, la independencia, la unidad de la patria y los valores superiores de la Constitución (art. 1), y se centra en ordenar su manejo: junto al escudo (arts. 2 y 3 ), señalando su ubicación (art. 3), relaciones con otras enseńas territoriales o nacionales (arts. 4 a 7), y la interdicción de su uso para entidades privadas, partidos, sindicatos o asociaciones (art. 8).

Por su parte, la Corona, como símbolo ${ }^{14}$, está dotada en el título II de una protección de extraordinario calado en el art. 56. $3 \mathrm{CE}^{15}$, cuando advierte de la inviolabilidad e irresponsabilidad de la persona del rey. Ahora bien, tan contundente declaración está aludiendo a una cobertura que no repercute directamente en la condición simbólica: así, se destina a remachar el eje de la monarquía parlamentaria «republicanizada» que nos hemos otorgado en la que la irresponsabilidad no surge de la posición regia, sino de la lógica de no poder imputarse ningún acto a quien no lo genera sino al que lo refrenda; mientras que la inviolabilidad, que sustenta un haz de protección que incluye la imposibilidad de juicio sobre el ocasional ejerciente de esta magistratura, tiene su basamento en la protección del Estado, y desaparece cuando esa persona que lo encarna abdica, renuncia o muere. En uno y otro caso no se trata

13 Los casos de la Ley 4/1983, de 4 de mayo, sobre uso de la bandera regional de Murcia; la Ley 2/1983, de 23 de diciembre, de bandera, escudo e himno de la Comunidad de Madrid; la Ley 2/1984, de 16 de abril, sobre uso de la bandera y el escudo de Aragón: la Ley 5/1984, de 29 de mayo, de símbolos de Galicia; la Ley 8/1984, de 4 de diciembre, por la que se regulan los símbolos de la Comunidad Valenciana y su utilización; la Ley 9/1984, de 22 de diciembre, de la bandera de la Comunidad Autónoma de Cantabria, o la Ley 4/1990, de 19 de diciembre, de la bandera del Principado de Asturias.

14 La naturaleza preeminentemente simbólica queda expuesta en estudios anteriores (Belda, 2003; 2015). La existencia del simbolismo, aunque fuere solo parcial, en el estatuto de la Corona es unánime en la doctrina española. La naturaleza de todos los reyes como símbolo, en Smend, 1994.

15 Art. 56. 3 CE: «La persona del Rey es inviolable y no está sujeta a responsabilidad. Sus actos estarán siempre refrendados en la forma establecida en el artículo 64, careciendo de validez sin dicho refrendo, salvo lo dispuesto en el artículo 65.2». 
de privilegios personales, inducidos por el espejismo de las palabras de inicio del art. 56.3 CE, sino tan solo el recuerdo de que estamos ante un símbolo permanente que debe ampararse objetivamente, separándolo de la persona que lo ejercita pero que en tanto asume esta alta magistratura recibe los reflejos de esa acción protectora ${ }^{16}$. La contundencia constitucional en proyectar sobre una persona concreta, el rey, una protección tan acusada en lo personal como es la inviolabilidad sí que está manifestando una opción clara por ensalzar el simbolismo de la Corona. Ahora bien, una cosa es que se dote de un estatuto jurídico-procesal muy reforzado a las jefaturas de Estado, sea cual fuere su forma, centrándolo en las personas que ocupan el cargo, y otra muy distinta es que lo que simbolizan sea indiscutible o intocable. La separación entre la protección de la persona y la de la idea que representa (la nación, la permanencia, la continuidad histórica, la unidad, etc.) es una consecuencia ineludible en cualquier lectura de los textos constitucionales de nuestro entorno. Y cierto es que la protección al símbolo lleva a reforzar la protección institucional, protocolaria o penal de la primera magistratura de un Estado como persona que lo refleja, pero de ello no puede derivarse automáticamente una proscripción constitucional de la idea, el espíritu, o la organización, discordante con tales valores. No obstante, quede constancia de la regulación constitucional en este sentido, frente a la ausencia de protección directa de la bandera, que será cubierta por la ley, o frente a la omisión de menciones a otros símbolos, como el himno.

\section{PROTECCIÓN CONSTITUCIONAL DEL USO DE LA SIMBOLOGÍA}

Bien es cierto que la protección de los símbolos tiene como fin el respeto del Estado como estructura, o incluso de la nación y de sus habitantes como reflejo, pero también destila una dimensión personal relativa al ejercicio de derechos que demandan ese simbolismo. Por ello, es muy relevante a nivel jurídico la cobertura de su uso por cada persona, incluso cuando sea crítico y alternativo. Es más, si detrás de tal hecho se encierra el ejercicio de un derecho fundamental, esta circunstancia sería de primera atención para el sistema de garantías. Hemos objetivado la defensa del símbolo como tema de este estudio, pero tal premisa no puede llevar a engaño sobre su naturaleza imaginaria de realidades personales y sociales escondidas tras el pensamiento y el

16 Belda (2015: 45-81) formuló propuestas de reforma para que la simbología y la representación no se contaminasen por hipotéticos actos indignos de quienes asumen la Corona. 
pluralismo, que se expresan (el mecanismo de exteriorizar también compone el derecho) por el símbolo. La doctrina acude a menudo a los ejemplos norteamericanos sobre comunicación simbólica que las banderas ofrecen (symbolic speech), y las colisiones con la libertad de expresión, para hacer presente la necesidad de conciliar la faceta del símbolo nacional como tal, y la utilidad alternativa del mismo para alertar sobre los problemas de la propia nación que simboliza. Troncoso (2018: 49-50) alude al manejo del asunto en la jurisprudencia del Tribunal Supremo de Estados Unidos y del TEDH para constatar que el uso alternativo de los símbolos se plantea en clave de ejercicio de libertad de expresión y fijación de límites de la misma: amparar críticas hasta la frontera del ultraje (Street v N.York, de 21 de abril de 1969, U.S $v$ Eichman, de 11 de junio de 1990) ${ }^{17}$. Esa tendencia parece encontrarse matizada en el TEDH ${ }^{18}$, siendo común en Europa reconducir por sistema la destrucción de símbolos a la libertad de expresión, y sus límites a la aparición del discurso del odio. El TEDH y el Tribunal Constitucional de España entienden que es suficiente para incitar a la violencia un peligro potencial, y se valora la dignidad de la persona para atajar la libertad de expresión de contenido xenófobo o racista. También hay diferencias en la negativa de hechos palmarios (p. ej., el negacionismo del Holocausto), que parecen amparados en Estados Unidos por la primera enmienda y el TEDH no lo acepta (Troncoso, 2018; Teruel, 2018a). Sin poder detenernos en este punto en la dinámica de conflicto entre el respeto al símbolo y la necesidad de canalizar mediante ellos pensamientos e ideas al amparo de la libertad de expresión, quede, en cualquier caso, constancia de que, en el aparato protector de la simbología del Estado, debe ser asunto de primer orden la protección de su uso (en el sentido que fuere) por las personas que en él habitan. Como enseguida veremos, la protección al uso de los símbolos supera con creces la endeble y cuestionada protección del símbolo como objeto, pues la primera deriva directamente de la libertad de expresión, y a través de ella, de otras, como las conformadas dentro del libre pensamiento y del conjunto de los derechos políticos propios del pluralismo.

Los pronunciamientos en el Supremo estadounidense reflejan una sostenida división de los magistrados, y prolongan la controversia, sin que pueda aseverarse una línea pacífica.

18 Sentencia Partido Popular Demócrata Cristiano c. Moldavia, de 2 de febrero de 2010. La línea, a la que más tarde volveremos y que se consolida en la sentencia Stern Taulats y Roura Capellera c. España, de 13 de marzo de 2018, asume dentro de libertad de expresión la destrucción de símbolos que no proyecte violencia hacia las personas. 


\section{CONCRECIÓN NORMATIVA Y JURISPRUDENCIAL DE LA PROTECCIÓN DEL SÍMBOLO Y DE SU USO: LA RESPUESTA ANTE LOS ATAQUES AL OBJETO Y A LA MATERIALIZACIÓN DE LOS DERECHOS MEDIANTE LA EXHIBICIÓN}

\subsection{Reacción ante el menoscabo de banderas o de la Corona como símbolo}

Interesa en el tema que nos ocupa, de manera preferente, el régimen de protección de cada símbolo, en la medida en que nos estamos centrando en las consecuencias de su transgresión frente a ataques o simplemente ante usos indebidos. Y para ello la normativa a la que hay que acudir es aquella a la que se remite el art. 10.1 de la Ley 39/1981, de 28 de octubre, para que regule ultrajes y ofensas (algo que, por tanto, no se deriva directamente de la protección del art. $4 \mathrm{CE}$ ), así como a la legislación que refleje consecuencias ante ataques a la figura del rey como símbolo (que, conforme se ha apuntado, la Constitución tampoco exige). En efecto, el legislador está en condiciones de sancionar el menoscabo de los dos símbolos constitucionales apelando a variadas razones que más adelante se expondrán, pero es muy conveniente recordar, como punto de partida, que la protección constitucional a cada uno de esos dos símbolos y la importancia que se deduce de su posición y su refuerzo ante la reforma no se acompañan de una exigencia expresa de penalizar el ataque. La cuestión clave parece estar en distinguir cómo la protección que arranca de los mandatos constitucionales puede ser de distinta naturaleza cuando de lo que se trata es de amparar instituciones o símbolos frente a cuando la finalidad es proteger personas y derechos.

Es el art. 543 del C. Penal el que ha venido castigando con penas de multa de siete a doce meses «las ofensas o ultrajes» a España, las comunidades autónomas, símbolos o emblemas, realizados por palabra, escrito, o de hecho, con publicidad. Ello supone que queda excluido el ámbito privado de acción o expresión y tan solo se trata de perseguir el hecho de la trascendencia y repercusión. Es preciso aclarar el ámbito u objeto de protección, pues las banderas estarían claramente aludidas por el hecho de ser símbolos de España o de las comunidades autónomas, pero el Código Penal impone el mismo castigo a los ataques hacia otros símbolos que, a diferencia de la bandera, no han contado con mención constitucional y que, por añadidura, su regulación ${ }^{19}$ (de distinta manera a lo que el art. 10.1 de la Ley 39/1981, de 28 de octubre, exigía para proteger la bandera) renunciaba a establecer remisión alguna a leyes de protección, siendo así que en la práctica el legislador penal los ha

19 Las normas ya citadas: Ley 33/1981, de 5 de octubre, del Escudo de España, y Real Decreto 1560/1997, de 10 de octubre, por el que se regula el Himno Nacional. 
terminado igualando ante el ultraje, haciendo irrelevante el distinto plano de reconocimiento de los diferentes símbolos por el constituyente.

El problema jurídico principal, entre los que se barajan de la protección objetiva de símbolos, surge a mi juicio en determinar si la Corona es objeto de la misma protección que banderas e himnos. Y quiero llamar la atención de cada persona que lea este artículo, pues esta perspectiva es clave para atender las pretensiones que aquí se persiguen, y supone una interpretación distinta a la barajada por la jurisprudencia española e incluso también con el enfoque (que no con el fondo) de las abundantes críticas sobre la misma: el art. 543 del Código Penal creo que es el único precepto aplicable frente al ataque a los símbolos, y ello incluye a la Corona. La protección de la misma como símbolo podría derivarse de una rápida lectura de los arts. 485 y ss. del Código Penal, que tipifican los «Delitos contra la Corona», y ello pudiera precipitar una impresión, incluso, de superprotección de tal institución por lo contundente de las consecuencias de cada uno de los tipos penales. Puede ser, pero solo en lo que respecta al jefe del Estado como persona y a los hombres y mujeres que de forma sustitutiva concurren con él en el desempeño de las obligaciones tasadas que tiene encomendadas. El legislador ha optado en línea con la tradición de derecho histórico y comparado en adjudicar en los tipos penales severas consecuencias ante los ataques a la integridad de la persona que ocupa la primera magistratura de la nación, pero inmediatamente hay que desentrañar del contenido de este grupo de preceptos que componen el capítulo II del Título XXI de la Ley Penal (Delitos contra la Constitución) cuando se trata de proteger la simbología de la Corona, pues la cobertura se ceñiría, a lo sumo, y en principio, a lo expresado en el art. 491.2 C. Penal: «Se impondrá la pena de multa de seis a veinticuatro meses al que utilizare la imagen del Rey o de la Reina o de cualquiera de sus ascendientes o descendientes, o de la Reina Consorte o del Consorte de la Reina, o del Regente o de algún miembro de la Regencia, o del Príncipe o de la Princesa de Asturias, de cualquier forma que pueda dañar el prestigio de la Corona». Y, en este caso, es también más que discutible que tal formulación permita castigar todo tipo de acciones adversas. Así, 1) el conjunto de preceptos penales de ese capítulo (arts. 485 a $491.1 \mathrm{C}$. Penal) están protegiendo la vida, integridad y otros derechos de las personas físicas que pueden asumir la función simbólica de la Corona; 2), el art. 491.2 C. Penal, se cuida de marcar todas las figuras constitucionales representativas de la Corona, por ello enumera la relación de todos los perfiles que pueden en un determinado momento no solo ocupar sino simbolizar el trono (de ahí que se incluyan ascendientes y descendientes), de cara a castigar acciones contra la imagen de cada figura para "dañar el prestigio de la Corona», es decir, de la institución y no de su magistratura unipersonal ni de los ocasionales 
ejercitantes de sus funciones simbólico-representativas. Por ello, solo en este supuesto se desplegaría por la ley penal, en sentido estricto, la protección al símbolo. Pero aun admitiendo esta premisa, 3) hay una más que dudosa continuidad de tracto reflexivo en asociar directamente como conducta típica acreedora de la aplicación de este precepto buena parte de las utilizaciones de imagen. Parece más acertado concluir que estaríamos ante la persecución de comportamientos privados cuya finalidad fuera menoscabar el crédito de la institución con cualesquiera finalidad limitada (p. ej., expresión de odio social, utilización con finalidades onerosas o para obtener influencias o prestigio social), pero no para frenar el normal desenvolvimiento de la crítica pública derivada del pluralismo político y la libertad de expresión hacia esta forma de jefatura del Estado o hacia lo que representa (España, Constitución, orden establecido, etc.). 4) Por último, y como sabemos, ha sido habitual la utilización del art. 490.3 C. Penal ${ }^{20}$, como no puede ser de otra manera, en la persecución de las injurias y calumnias hacia el monarca y su entorno. Tan lógico es que exista un precepto en este sentido para proteger la persona de quien desempeña un cargo constitucional de trascendencia como que, por ese mismo hecho, y como ha dejado palmariamente claro el Tribunal Europeo de Derechos Humanos ${ }^{21}$, se deba contemplar la aplicación de tal norma punitiva en total sintonía con los márgenes de la libertad de expresión y en el contexto del pluralismo democrático, lo que parece que urge a una revisión de este precepto (Presno, 2018: 549), o al menos de las gravosas penas que asocia ${ }^{22}$. La

20 Art. 490.3 C. Penal: «El que calumniare o injuriare al Rey o Reina a cualquiera de sus ascendientes o descendientes, a la Reina consorte o al consorte de la Reina, al Regente o a algún miembro de la Regencia, o al Príncipe o Princesa de Asturias, en el ejercicio de sus funciones o con motivo u ocasión de éstas, será castigado con la pena de prisión de seis meses a dos años si la calumnia o injuria fueran graves, y con la de multa de seis a doce meses si no lo son».

21 Véase Presno, 2018: 539-549. Este autor ejemplifica con la STEDH Stern Taulats y Roura Capellera c. España, de 13 de marzo de 2018, pero alude en su artículo a numerosas resoluciones anteriores de ese Tribunal que edifican una sólida referencia protectora de la libertad de expresión, en especial frente a la determinación de los límites en las opiniones o críticas sobre todo tipo de servidores y cargos públicos, de manera sostenida en el tiempo, que no constituyen ataques desproporcionados (p. ej., Handyside v. Reino Unido, de 7 de diciembre de 1976, Castells c. España, de 23 de abril de 1992, Otegui Mondragón c. España, de 15 de marzo de 2011).

22 La tendencia histórica a disminuir las consecuencias frente a este tipo de afrentas es particularmente reseñable en el caso español, especialmente cuando en el anterior régimen político el simbolismo era objeto de permanente exaltación, y ello tenía su correspondencia en la sanción penal. A diferencia del art. 123 del Código Penal de 
doctrina penal también incide en las distorsiones de congruencia en las aplicaciones del tipo (Queralt, 2013).

Pero es que conviniendo que la línea del Tribunal Europeo de Derechos Humanos exige aceptar sin más prolongación del debate un nivel de crítica que, según se desprende de la jurisprudencia que conocemos y a la que Presno (2018) alude, puede elevarse notoriamente de tono (exagerarse y encerrar extremos difícilmente digeribles por los aludidos y por la sociedad, sin sobrepasar lo admisible en la crítica política, bajo el amparo de la libertad de expresión y el pluralismo), en los casos enjuiciados en el ámbito nacional y europeo estamos ante dos tipos de comportamientos distintos. Y es que, en asuntos como el Castells c. España, de 23 de abril de 1992, o el Otegui Mondragón c. España, de 15 de marzo de 2011, se realizan acusaciones, críticas o ataques frente al rey como persona que ocupa una magistratura unipersonal, y que en el imaginario de los sectores a los que representaban los señores Castells y Otegui realizaba directamente el papel de opresor, torturador, etc. $\mathrm{O}$ en el caso Eon c. Francia, de 14 de marzo de 2013, el manifestante llamaba "pov'con» al presidente de Francia a su paso y en persona. Mientras, y esto es lo trascendente, en asuntos como el contenido en la sentencia Stern Taulats y Roura Capellera c. España, de 13 de marzo de 2018, lo que se produce es una quema de las fotos de los reyes de España, del símbolo, no de sus augustas personas (a las que no se insulta, ni injuria, ni agrede), en un ambiente de manifestaciones contra la Corona, la dinastía histórica y el orden territorial español. De nuevo, pues, la distinción: no puede ser lo mismo quemar al rey que quemar su foto, y naturalmente que la comunidad política puede proteger la faceta meramente simbólica de la figura, pero para ello habrá de construir una respuesta (penal o no) acorde con la entidad de los hechos, sin poder asimilarlos al ataque efectivo a la persona. En España existe, como nos recuerda el propio Tribunal Constitucional en la STC 177/2015, de 22 de julio, FJ 3, la intención estatal de proteger la figura del rey dentro de los delitos contra la Constitución, en lo que a las injurias hacia el mismo se refiere, y no los contempla dentro del capítulo que protege el derecho al honor, pero esa lógica protección de la magistratura unipersonal en la que se habilita una cobertura por el cargo que ocupa, y naturalmente por lo que simboliza, no parece que sin más explicaciones pueda extenderse como habilitación para perseguir y

1973, en el art. 543 de esa norma, en las décadas siguientes, se disminuyen los castigos y se restringe la penalización a las conductas con repercusión pública. La inconstitucionalidad de una declaración legal que suponga que cualquier ultraje a la bandera se comete con publicidad (antiguo art.10.3 de la Ley 39/1981, de 28 de octubre), en la STC 118/1992, de 16 de septiembre. 
castigar ataques a la imagen refleja, a lo simbolizado, a lo representado. La jurisprudencia espańola mantiene la línea, parece que acertada, sin entrar en el debate de la magnitud de las penas, de aplicar el art. 491.2 del Código Penal cuando efectivamente se injuria a la persona del jefe del Estado sin finalidades políticas adicionales (Juzgado Central de lo Penal núm. 1, en sentencias $16 / 2013$, de 14 de marzo, o 3/2016, de 26 de enero ${ }^{23}$, pero ello no parece sostenerse cuando la afrenta es a la idea.

Si la jurisprudencia del Tribunal Europeo de Derechos Humanos concluye la compatibilidad de ciertos comportamientos ofensivos, directamente ejercitados contra personas que ocupan cargos y magistraturas constitucionales, en un ambiente de libertad de expresión y pluralismo, ni que decir tiene que admite la posibilidad de afrentas a sus imágenes que, en el caso de los reyes, de manera directa por la Constitución española, son elevados a la condición de símbolos. En el caso Stern Taulats y Roura Capellera c. España, de 13 de marzo de $2018^{24}$, los órganos de justicia de España ${ }^{25}$, y el Tribunal Constitucional (STC 177/2015, de 22 de julio), mantuvieron el criterio que identifica el insulto a la persona del rey, con la crítica de aspecto insultante hacia la Corona como símbolo de las estructuras del Estado y de Espańa, aplicando el art. 490.3 del Código Penal. Describen como injurias a la Corona lo que el propio precepto ignora, al referirse textualmente a personas (rey, reina, regente, príncipe, etc.), dando por sentado que quien quiera criticar la monarquía no tiene por qué «vilipendiar» o «menospreciar» a los reyes ${ }^{26}$, por la quema y colocación boca abajo de sus imágenes. Incluso llega el Alto Tribunal a suponer que ello está trasladando la idea de un ajusticiamiento efectivo de los fotografiados ${ }^{27}$.

23 Se trata de insultos directos y probados contra la persona del monarca, no solo contra la forma de la jefatura del Estado y su imagen. De interés, sobre los ataques al honor de la Corona, Fernández-Sarasola, 2019.

24 Véase un resumido análisis en Presno, 2018: 546-548.

25 Sentencia del Juzgado Central de lo Penal de la Audiencia Nacional de 9 de julio de 2008 y Sentencia de la Sala de lo Penal de la Audiencia Nacional de 5 de diciembre de 2008.

26 Asociación realizada por la Sentencia del Juzgado Central de lo Penal de la Audiencia Nacional de 9 de julio de 2008, que no cuestiona el más alto tribunal de garantías.

27 STC 177/2015, de 22 de julio, FJ 4. Incita al odio, afirma este mismo FJ. Eso sí que puede ser, como también lo hace cualquier palabra contraria a los que los potenciales odiadores consideren como su credo intocable. Pero no es el odio descrito jurisprudencial o doctrinalmente como limitativo de la libertad de expresión, que no se observa que concurra en este supuesto (Presno, 2018: 544). En este extremo me 
Sin necesidad de detenernos más sobre este supuesto, puede observarse que la justicia ordinaria y constitucional española, cuarenta años después de la promulgación de la Carta Magna, parece no reconocer aún la naturaleza eminentemente simbólica de la Corona, y lo que es más preocupante que eso, la naturaleza totalmente simbólica de una fotografía, desde que Niépce la inventara en 1825 . No quiero detenerme en este párrafo cultivando un instinto iconoclasta, sino tan solo manifestar que, si admisible es un elevadísimo grado de crítica hacia la persona pública, en principio y salvo que se argumenten las bases que lo imposibilitaran, admisible sería tal crítica hacia un símbolo. Y podrá o no compartirse que la Corona es ya, y no es poco, principalmente símbolo, como la bandera o el himno, pero lo que parece difícil de negar es que los retratos de los reyes lo son siempre, hasta cuando la monarquía no era símbolo sino poder efectivo ${ }^{28}$. En el asunto Stern Taulats y Roura Capellera $c$. España, en todo caso y sin género de dudas, el TEDH establece que la quema o la crítica es al símbolo, a lo que representa (núm. 38), en línea con lo expresado años atrás en otro asunto similar de quema de signos y retratos de representantes públicos adversarios (Partido Popular Democratacristiano c. Moldavia, de 2 de febrero de 2010).

Por todo ello, reitero que el campo de protección penal de la Corona como símbolo, que es necesario, pero no asimilable a la protección de la magistratura constitucional (de la persona que es rey), debería partir, en su caso, del genérico y más benigno art. $543 \mathrm{C}$. Penal, y recibir así un tratamiento conjunto con el resto de símbolos, en especial con las banderas. La ley penal está en condiciones de proteger a las personas que ocupan cualesquiera posiciones constitucionales con preceptos ad hoc o con el establecimiento de circunstancias modificatorias de la responsabilidad criminal como puedan ser los agravantes, pero no parece que encierre la identificación de personas y

remito a las cada vez más numerosas contribuciones que analizan el discurso del odio como límite a la libertad de expresión (Teruel, 2018b, Martín Herrera, 2018, o López Ulla, 2017, entre decenas de investigadores). Véase también, a modo de ejemplo, la STEDH caso Feret c. Bélgica, de 16 de julio de 2009.

28 La separación de la simbología respecto de los cargos públicos objeto de crítica ha de actuar a mayor abundamiento de la necesaria permisión de la misma. No nos detenemos en el detalle de las operaciones de ponderación y análisis que admiten en el seno de una sociedad democrática todo tipo de exteriorizaciones de la opinión pública, incluyendo las que más repulsa general puedan suscitar, tema que por extensión requiere de estudios específicos. Recordemos, asimismo, la exigencia del Tribunal Europeo de Derechos Humanos para restringir la legislación y el proceso penal como escudo protector de instituciones e ideas, por encima de los derechos de las personas (caso Jiménez Losantos c. España, de 14 de junio de 2016). 
símbolos de tal manera que desarrolle un estatuto de intangibilidad para la crítica institucional porque quiera reforzar a sus ocasionales titulares. Nunca dañar o quemar la imagen del representante de cualesquiera poder u órgano podrá lejanamente asimilarse a proceder efectivamente contra su persona. En definitiva, la estructura estatal de protección de sus símbolos constitucionales, bandera y Corona, se manifiesta a través de preceptos que plasman su utilización, y de un resorte penal que les protege de los ataques, el art. 543 C. Penal.

Las dudas en torno al proceder de nuestra justicia frente a las afrentas a los símbolos se extienden también a las banderas e himnos. Aguilera y Vernet, hace ya décadas (1993: 156), advertían del hecho de que el Tribunal Supremo venía anudando el delito de ultraje a la bandera con las injurias, aplicando respecto del primero la doctrina mantenida para las segundas. Ha pervivido largo tiempo la retórica, inconcreta y de escaso valor jurídico, que denunciaban estos autores (Aguilera y Vernet, 1993: 157) para apuntalar la asociación entre ultraje a la bandera y afrenta contra el sentimiento de la nación ${ }^{29}$. Desde el derecho penal (Vázquez-Portomeñe, 2002: 48), también se apunta esta crítica. Otras afrentas simbólicas muy mediáticas, como la pitada al himno nacional (que en ocasiones es concurrente con la pitada al jefe del Estado, cuando está presente), a pesar del rechazo social que suscita en la mayoría de la población, terminan quedando sin consecuencias por regla general, dada la preeminencia de la libertad de expresión en la concurrencia de los hechos (Juzgado Central de Instrucción núm. 4 de la Audiencia Nacional, Auto de 18 de febrero de 2016, con alusión expresa del art. 10 del Convenio Europeo de Derechos Humanos) ${ }^{30}$. La ponderación de los hechos y la proporcionalidad de las respuestas parecen presentarse como la clave previa a todo el tratamiento jurídico, aunque ello pueda generar una apariencia de praxis judicial oscilante (Ridao, 2019).

En fin, para terminar estableciendo que existe ataque al símbolo se debe de llegar a determinar que concurre una ofensa o ultraje, y, primero, no es

29 Las sentencias de los primeros años de desarrollo constitucional, p. ej., la STS 4060/1981, de 7 de febrero, siguieron la estela de resoluciones preconstitucionales (SSTS de 6 de junio de 1968 o 21 de noviembre de 1969). Ya se concluía hace varios lustros la necesidad de huir de respetos impuestos a golpe de sanciones penales desproporcionadas (Aguilera y Vernet, 1993: 160). La proporcionalidad en la respuesta pública ante ataques a los símbolos es una constante en la práctica totalidad de los estudios al efecto.

30 Se archiva la causa por pitadas al himno de España en presencia del rey, no percibiendo en los hechos ni injurias al jefe del Estado, ni apología del odio, ni la concurrencia de los ultrajes a Espańa, que llevarían a aplicar el art. 543 C. Penal. 
fácil concluir, tras la mayoría de actitudes y pronunciamientos críticos con los mismos, que tal proceder sea ofensor o ultrajante, y segundo, y esto es lo más importante, que resulte siempre concluyente cualquier juicio punitivo que declare la efectividad del agravio, cuando, a diferencia de lo que ocurre con las personas que se manifiestan perjudicadas, el símbolo no lo puede hacer. Como puede comprobarse, los poderes públicos tienen que edificar una ficción de objetividad, se supone que, estableciendo una serie de parámetros transgresores de los símbolos, para llegar a ofrecer un paraguas protector a los mismos, que se basará en meras convenciones sociales. Y aquí reside uno de los ejes de la cuestión que nos trata: la envergadura de la construcción pública de protección de los símbolos, llegado el momento de confrontación real con su ataque, habitualmente basado en sólidos pilares derivados del ejercicio de la libertad de expresión, ideológica, de pensamiento, y de los derechos políticos, se muestra notablemente disminuida y filosóficamente desamparada. Si comparamos lo que desde la perspectiva de los derechos y libertades se gana admitiendo un amplísimo margen de crítica hacia ellos frente a lo que se pierde con el riesgo de ultrajes y ofensas hacia los frutos de una convención social, la balanza se inclinaría por dejar en desuso las prescripciones protectoras, especialmente las penales, y soslayar las manifestaciones de afrenta, que sucumbirían ante la amplitud que proyectan los derechos de las personas críticas. Y todo ello sin contar que una protección penal, basada en la persecución y castigo de comportamientos intencionados en delitos de esta naturaleza, requiere la concurrencia de elementos acompańantes, que no siempre aparecen, y cuando lo hacen disponen de difícil prueba. Así, la persona que quema una bandera o la imagen del rey para pedir la independencia de su territorio puede o no proyectar una actitud de ofensa a España, o a su comunidad autónoma, a través de la quema de sus símbolos, querer o no ultrajar, pero lo que sí es cierto es que está expresando una opinión adversa al orden establecido a través de aquello que lo simboliza, y ese trasfondo estará siempre presente para el operador jurídico que lo valore ${ }^{31}$.

\subsection{Reacción ante las trabas al uso de la simbología para la expresión personal y la canalización del ejercicio de otros derechos}

Frente a la desguarnecida línea de protección que en nuestros días presenta la protección a cada uno de los símbolos, se alza con suficiente solidez

31 Más ejemplos de afrentas simbólicas en Alemania, Francia o México en Brage, 2008: 41-42. 
un haz reactivo para resguardar la utilización de símbolos a través de la libertad de expresión, reforzada con los derechos y libertades que la respaldan y de los que constituye cauce de materialización (pensamiento, ideología, derechos políticos, concretando todos ellos los valores de libertad y de pluralismo político). Su ámbito es jurisprudencialmente consagrado con considerable amplitud ${ }^{32}$ formal y práctica (SSTC 127/2004, de 19 de julio, FJ 4, y 9/2007, de 15 de enero, FJ 4, o STEDH Perinçek c. Suiza, de 15 de octubre de 2015), con el límite explícito en nuestro ámbito de no incurrir en el discurso del odio ${ }^{33}$, lo que, piénsese, es fácticamente más complicado en la dinámica de utilización de símbolos o de su presunto ultraje que en la crítica a personas.

Partiendo de esta realidad y del acuerdo que mantenemos con esta concepción protectora mayoritaria, tan solo se quiere dejar apuntada esta posición a efectos de la sistemática y comprensión de este estudio, para continuar con nuestros objetivos y aportaciones. Ello no excluye que este campo relativo al uso de los símbolos como ejercicio de derechos y libertades siga demandado de progresos, muy especialmente en la extensión de los límites.

\section{LA NECESIDAD DE RESPALDAR LOS SÍMBOLOS EN SENTIDO ESTRICTO CON ARGUMENTOS CONSTITUCIONALES DE PESO}

En definitiva, el panorama de protección de los símbolos presenta dos caras, por una parte, la protección objetiva de la simbología del Estado, que adolece de cierta debilidad para sustentar las consecuencias que plantea ante el mal uso o el ataque a las banderas, la Corona y demás simbología, y, por otra, la protección de los sujetos que usan los símbolos para el ejercicio de sus derechos y libertades, que es una coraza sobre los símbolos indirecta, pues en realidad se trata de la decidida cobertura del contenido de derechos como la

32 Con ciertos retrocesos argumentativos, como los reflejados en STEDH Sinkova v. Ukraine, de 27 de febrero de 2018.

33 Por todos, Teruel, 2018b: 13-45. Este autor también critica la línea del Tribunal Constitucional español por su amplitud de cánones y la «[...] aplicación concreta a partir de genéricas presunciones y de pretendidas idoneidades sin un auténtico sustento fáctico como ofensas» (Teruel, 2018b: 29). La respuesta al discurso del odio debe ir más allá de lo penal o de la sanción administrativa, aunque esa respuesta haya de seguir estando presente. Así, «[...] considerar amparada [...] una determinada idea no quiere decir "santificarla" [...]» (ibid.: 41), solo no reprimirla. Sobre articular el concepto de «discurso del odio», en torno a la incitación, véase Rollnert, 2019b. 
libertad de expresión, que sí disfruta de una espesa protección constitucional y jurisprudencial.

En el reinado absoluto y bien ganado de los derechos fundamentales en los Estados sociales y democráticos de derecho, la posición jurídica de los símbolos parece exigir una lectura que los respalde suficientemente, pues paradójicamente la protección del uso del símbolo genera a la vez un riesgo potencial para el símbolo objetivamente considerado. Y no basta con encontrar el buscado fortalecimiento en formulaciones genéricas de naturaleza ideológica, histórica, tradicional, social o antropológica ${ }^{34}$, si tras todo ese basamento sustancial no se encuentra un aparato normativo consistente. ¿Dónde engarzarlo? ¿También en los derechos, principios y valores? Necesariamente sí: ese es el camino de la supervivencia del símbolo público o institucional ante la expansión lógica de la libertad de expresión en un ambiente de libertad y pluralismo político. De lo contrario, esperar a que solo los ataques más execrables y feroces que incluso sobrepasaren el amplio margen que destila la libertad de expresión para llegar a esos excepcionales casos (por todos, los del discurso del odio $^{35}$ y los ataques a la dignidad sobre hechos palmariamente inveraces STC 214/1991, de 11 de noviembre- ${ }^{36}$ ) donde no llega a posibilitar el amparo, terminarían dejando como respuesta solo la repulsa o el rechazo social de las mayorías respetuosas con la simbología. Esa solución no puede satisfacer al derecho, en tanto que las constituciones han entendido que los símbolos requieren protección. Tampoco las alusiones a principios desactualizados como el orden público (Sánchez de Diego, 2011) permiten encauzar un baluarte de respeto mínimo, a la luz de cómo se está expresando la jurisprudencia del TEDH. Incluso merecería la pena preguntarse si es necesario el hecho mismo de buscar pilares defensivos sobre lo simbólico, dado su naturaleza impersonal. Creo que, además de la letra de la Constitución, hay más argumentos para dotar de contenido significativo para la organización social a los símbolos del que se ha dado, pero, en cualquier caso, el camino de la protección efectiva de los símbolos del Estado debe mantener un recuerdo

34 Moreno y Núñez, 2018: 381-393. En estos historiadores encontramos una visión actualizada del ambiente de inadaptación simbólica, y la dinámica de las afrentas

35 Stern Taulats y Roura Capellera c. España, de 13 de marzo de 2018, 33. Sürek c. Turquía, de 4 de diciembre de 2003, 62.

36 El caso de Violeta Friedman. Es importante recordar en esta resolución (FJ 8) la conexión con la dignidad de la persona y de grupos de personas, que se deriva del establecimiento de límites a la libertad de expresión en casos marcadamente execrables como el presente, que son representativos de la interdicción del discurso del odio, pero también de una defensa de valores y principios colectivos. 
permanente a su naturaleza «disponible» para las personas, es decir, a su carácter instrumental para el mejor ejercicio de las libertades de expresión, pensamiento y las políticas, pues de esa manera se logrará la adecuada ponderación de las consecuencias (proporcionadas) que el ordenamiento debe establecer ante los ataques a los símbolos. Es cierto, recuerda Brage, que, como en Estados Unidos o Alemania, mejor que primen los derechos fundamentales por mucha que sea la importancia de los símbolos (Brage, 2008: 43), pero sin olvidar que los segundos también mantienen un enlace con derechos de primer orden.

Puede construirse un traje protector a la bandera y a la Corona, que dará mayor resguardo si en sus telas se barajan elementos relativos a los derechos de las personas que se ven reflejadas en ellos, y no solo si se apela a elementos inmateriales; pero ese ropaje, forzosamente, se presentará como más liviano, y por ello permeable, que aquel otro con el que se viste la protección del uso de los símbolos para expresar el pensamiento, las ideas y las opciones políticas. El camino, por tanto, es concluir abiertamente que se trata de proteger el ámbito personal de la dignidad y de las creencias, que siempre tienen que ver con una serie de derechos y libertades. No solo se trata de aceptar la necesidad de canalizar ese sentimiento como otros elementos «irracionales» reflejados en la Constitución, aunque también sea el caso. Veamos.

Las constituciones que responden a la realidad deben entender con naturalidad la existencia de espacios y elementos «irracionales»" ${ }^{37}$ que también están presentes en la organización social y atraen al ser humano (Alegre, 2008: $10)^{38}$. Estos elementos mantienen unido al pueblo en los aspectos íntimos (Häberle, 2012: 96) y las constituciones los acogen como una identidad cultural que las vivifica (ibid.: 107) ${ }^{39}$. Häberle es, precisamente, uno de los autores que con más claridad racionaliza determinados símbolos del Estado, con una adecuada actualización: además del Estado, se simboliza una dimensión cultural y «multicomunitaria» (Mikunda, 2008). También el Estado como estructura se beneficia del simbolismo ya que la comunidad política a través de banderas o himnos se conecta con él (Vernet, 2003: 107). El símbolo

37 Troncoso (2018: 32) subraya cierto aspecto irracional del simbolismo, apelando a Sperber.

38 Siguiendo a Häberle. Smend ya había hablado concretamente de esa irracionalidad subrayando la capacidad de los símbolos para ser más moldeables que otro tipo de formulaciones (Brage, 2008: 29).

39 Esa identidad cultural, a diferencia de otros aspectos meramente instrumentales como p. ej. la libertad económica, se basa en la dignidad del hombre y requiere en su determinación un marco pluridisciplinar (Häberle, 2012: 99-100). 
manifiesta plásticamente una idea, y sus contenidos irracionales permiten transmitir un significado no accesible a las palabras. Y de manera rápida y automática (Tribunal Supremo de Estados Unidos, Caso Texas v. Johnson, de 21 de junio de 1989) ${ }^{40}$. Identifica y une, aunque también diferencia de otro u otros (Brage, 2008: 23). La simbología de una nación está contenida en la psicología colectiva. Su plurivalencia es clave y tiene la fuerza de integrar realidades heterogéneas (Troncoso, 2018: 33) ${ }^{41}$. Los símbolos cumplen una función representativa y también otra integradora ${ }^{42} \mathrm{o}$ de transmisión condensada y emocional de los valores y la historia de una comunidad política (Brage, 2008: 24-26). Y en el caso de Espańa esa fue la finalidad del art. $4 \mathrm{CE}$, resumiendo toda esa ambivalencia: un precepto de dimensión política en el que la Constitución se manifiesta como norma de integración, fortaleciendo al sujeto constituyente (Solozábal, 2008: 74). Las banderas representan con un cuerpo y tangibilidad, como símbolos que son, las realidades políticas a las que se refieren. Nación y Estado no son realidades inmediatas y así se pueden escenificar (ibid.: 75) ${ }^{43}$. Para este autor, ya la STC 94/1985, de 29 de julio, marca tres claves sobre el significado político de los símbolos: 1), que tienen una función identificadora (por su sencillez tienen capacidad de captar a las masas); 2), impulsan y refuerzan la identidad del colectivo y de su comunidad (con elementos de continuidad y tradición que influyen en lo emocional), y 3) externalizan la comunidad política y la singularizan (FJ 7).

Singularización de la comunidad, identificación en ella del individuo e instrumento de movilización hacen del símbolo, como puede comprobarse, un componente de relevancia para las personas y la comunidad política. Las primeras, de la misma forma que son representadas por otras personas en el ejercicio de las funciones públicas del territorio, disfrutan, asimismo, de una imagen simbólica para encarnar su identificación individual y colectiva. Es un aspecto que demanda protección estatal y así lo han entendido la Constitución y el ordenamiento. Bien es cierto que no llega a ser, ni debe, de la

40 La bandera identifica tan rápidamente a una nación como su nombre.

41 Siguiendo a Ricoeur: dice más de lo que no dice y de lo que jamás termina de decir (Troncoso, 2018: 33).

42 Brage (2008: 28) recuerda que el primer teorizador del valor integrador de los signos, desde la perspectiva jurídico-constitucional, fue Smend (1985: 107, pertenencia emotiva a una colectividad).

43 Los símbolos singularizan la comunidad política y la distinguen de otras, publifican los eventos separándolos de los actos privados. También identifican al individuo con la comunidad a la que pertenece. A través de su vertiente utilitarista sirven para movilizar y reivindicar (potencial político). 
misma envergadura que los mecanismos reactivos que amparan la persona y la labor de los representantes políticos que asumen la representación pública primera y fundamental de cada ciudadano, pero al menos hay una constancia de que aspectos valorables del sentimiento de personas y grupos de personas pueden reflejarse en un objeto, llámese bandera, himno, rey o escudo. Por ello, cuando se protege un símbolo, hay una cobertura de espacios y aspectos emocionales que sí tienen interés para el derecho, y que se encuentran con facilidad amparados en derechos humanos y fundamentales que sirven para alimentar un sustrato de protección al símbolo: libertades de pensamiento, ideología, expresión, credo, participación, identidad cultural, etc. Mientras que, para el Estado y sus estructuras políticas y administrativas, funcionan como un mecanismo de articulación de relaciones que recuerda la presidencia del pueblo en la toma de decisiones y en el diario desenvolvimiento del servicio público: el símbolo funciona en esta dimensión como objetivación de aspectos ciudadanos y comunitarios que no tienen una correa de transmisión tan obvia como la que se ejercita a través de la representación política. Sirva el siguiente ejemplo para distinguir ambas necesidades de representación de cada ciudadano/a o de cada conjunto de ciudadanos, y con ello demostrar que los símbolos complementan la presencia del pueblo en la cosa pública: si estamos preocupados por nuestras prestaciones sociales, participamos en los asuntos públicos directamente o a través de nuestros representantes, y mediante el ejercicio de numerosos derechos de variada naturaleza (libertad de expresión, sufragio, manifestación, sindicación, etc.), intentamos trasformar la realidad para conseguir un objetivo. Mientras que si lo que queremos es expresar un aspecto inmaterial de nuestras preocupaciones, motivaciones o anhelos, demandamos una referencia para exteriorizar sentimientos (de protesta, de agradecimiento, de reconocimiento, de unidad, de rechazo, etc.), y para eso está la simbología en sentido estricto. El símbolo, figura u objeto que resume, tiene manifiestamente un valor como instrumento o remedio menor que el ejercicio de los derechos, que están diseñados específicamente para satisfacer necesidades inmediatas e incluso jurídicamente carece de relevancia práctica. Sin embargo, su naturaleza abierta e inespecífica sirve para canalizar los espacios individuales y colectivos que complementan la relación constitucionalmente establecida por cauces reglados entre las instituciones y las personas: unifican espíritus, mensajes, expresiones, pertenencias e identidades culturales, tanto para reivindicarlos como para rechazarlos.

Y así, no parece que la protección del símbolo pueda estar a la misma altura en las preocupaciones del sistema político que la protección de las personas y de sus derechos, pero sin duda es relevante, ya que la finalidad no es 
proteger el símbolo sino lo que simboliza, y en ese contenido se encuentran también derechos de las personas, concretamente mecanismos de exteriorización de deseos, percepciones, anhelos, recuerdos o ideas, tanto personales como colectivos ${ }^{44}$, que en mayor o menor medida se engarzan con su dignidad, su personalidad y su libertad. Y que desde esos principios y valores son relevantes en la integridad psíquica, la libertad de pensamiento en sentido amplio, la expresión, la participación política, o el ejercicio de los derechos culturales e identitarios, por llamar en esta relación a los derechos y libertades prima facie más reconocibles. El símbolo reconocido en el Estado de derecho consagra un paso del mito a la razón, camino que está en el propio nacimiento del Estado de derecho (García Pelayo, 1991[1964]: 1005 ${ }^{45}$ ), canalizando la utilización del mismo como elemento, parte o componente que se puede reconocer en derechos y libertades.

Esta presencia indirecta de los derechos en el símbolo es similar a la que se observa en el caso de Violeta Friedman (STC 214/1991, de 11 de noviembre, FJ 6 in fine) cuando el Tribunal Constitucional relativiza el componente intrínsecamente personal de la vulneración del derecho al honor al señalar la posibilidad de una afección al mismo desde ataques «innominados, genéricos e imprevistos». Así, por ejemplo, una afrenta a la bandera que sentimos como propia no puede traducirse en un ataque personal a nuestro honor o a nuestra dignidad, pero no por ello quedamos inmunizados objetivamente: la realidad es que sí podemos llegar a sentir, individualmente, algún tipo de afectación. Ello, bien es cierto, debería de ser asumido personalmente como un precio que justifique el respeto por el ejercicio de derechos ajenos, pero no por esto dejan nuestro honor o dignidad de sufrir una cierta afrenta, por muy tolerable que pudiera llegar a ser. La sociedad está en condiciones de habilitar algún tipo de compensación para ello, coherente, proporcionada y limitada, pero reconocible: no olvidemos que también estamos «usando» continuamente nuestros símbolos cuando cotidianamente se exhiben sin perturbación o menoscabo. Y ello es tan relevante como cuando otras personas o nosotros mismos los manejamos para la crítica. La presidencia simbólica de los espacios públicos termina expresando un sentimiento de cada persona de manera sostenida.

44 Las afectaciones emocionales de terceras personas son resaltadas en la ya citada sentencia del Tribunal Supremo de Estados Unidos en el caso Texas v. Johnson, de 21 de junio de 1989, sobre quema de la bandera, aunque sobre ellas prevalece la libertad de expresión (Brage, 2008: 39-40).

45 El símbolo como medio de expresión de la conciencia mítica encauza lo irracional hacia la utilización racional. 


\section{LA CONVIVENCIA DE LA COBERTURA DEL USO CIUDADANO DE LOS SÍMBOLOS, CON SU PROTECCIÓN COMO OBJETOS, SIN AFECTAR DERECHOS Y LIBERTADES}

Parece pacífico concluir que la libertad de expresión de cada persona, complementada con otros valores (libertad, pluralismo político) y derechos (participación política, manifestación, etc.), permite un uso o una crítica de amplísimo espectro de los símbolos constitucionales. Y muchas de nuestras constituciones, siguiendo a la Declaración Universal de Derechos Huma$\operatorname{nos}^{46}$, por añadidura, consagran expresamente la apertura de caminos de expresión que indubitadamente incluyen a los símbolos como su cauce (art. 20.1 a CE, art. 21 de la Constitución italiana, art. 5 de la Constitución de Alemania, art. 37 de la Constitución portuguesa $)^{47}$. De la misma manera que, tras esa premisa, no pueden plantearse un conflicto o una colisión directos con las libertades y derechos también personales que los símbolos proyectan, pues tal confrontación es claramente desequilibrada, ya que en el primer caso el uso del símbolo o su crítica sirve directamente para ejercitar un derecho o libertad, mientras que en el segundo caso el símbolo tan solo (aunque no sea poco) va a reflejar una representación de contenido variable, subjetivo y abierto, de creencias, valores o sentimientos protegidos por los derechos y las libertades. El valor de esta afectación es, creo, el criterio que el creador de la norma protectora sobre los símbolos tiene que utilizar para determinar una consecuencia ante las vulneraciones y ataques que sufran, estableciendo la misma sin perder de vista que no se trata de una afrenta tan inmediata y probada como la que se produce reprimiendo el uso simbólico en el ejercicio de derechos y libertades (que es lo que impide plantear una colisión de derechos equilibrada). Se trataría solo, pero necesariamente ante la implicación de derechos y libertades personales y comunitarios, reales y reflejados por los símbolos, de establecer alguna suerte de «compensación» para los afectados,

46 Art. 19 DUDH: «Todo individuo tiene derecho a la libertad de opinión y de expresión; este derecho incluye el de no ser molestado a causa de sus opiniones, el de investigar y recibir informaciones y opiniones, y el de difundirlas, sin limitación de fronteras, por cualquier medio de expresión».

47 La Carta italiana utiliza la fórmula "cualquier otro medio de difusión», línea que sigue España (cualquier otro medio de reproducción). El art. 5 de la Constitución alemana se refiere, entre otras, a la exteriorización de pensamientos e ideas «a través de la imagen", y en similares términos se pronuncia el art. 37 de la Constitución portuguesa, que protege la divulgación a través de «la imagen o por cualquier otro medio". 
que han percibido un desprecio en sus creencias, ideas o sentimientos, pero los mismos no están constitucionalmente sujetos a indemnidad, ni tendrían forma, dada su naturaleza inespecífica, de mostrarse de manera absoluta. Este componente "subjetivo», claramente dañado por críticas ajenas en general y en el caso concreto que tratamos por usos o afrentas simbólicas, debe convivir con la libertad de expresión y el ejercicio de derechos concordantes, por lo que al respeto que puede aspirar es el que se convenga tras fijar una imagen básica (reconocimiento jurídico del hecho de que los símbolos materializan sentimientos de personas y colectivos, que están relacionados con valores y derechos protegidos constitucionalmente), lo que ya hace el Estado cuando protege a los símbolos, ańadiendo una consecuencia jurídica equilibrada y proporcional al menoscabo de esa realidad. En esa consecuencia, como aquí se expone, es donde entra en juego la determinación del "valor» de la afectación: el legislador, según el estado de cosas de la sociedad receptora de la norma, "calcula» la magnitud de la respuesta, estableciendo una consecuencia penal o administrativa (p. ej., una sanción pecuniaria que se dedique a gasto social). Es de esta manera cuando, no los símbolos, sino lo que significan, se protegen razonablemente, y escapan de una cobertura neutra o arbitraria, para justificar, si fuera el caso, una penalización de las conductas por menoscabo de derechos y libertades «reflejadas» por la bandera o el rey, y no por la protección del símbolo por el hecho de serlo.

Siguiendo con el ejemplo de España, el art. 16.1 CE y el art. 20.1 CE extienden un amparo sin ambages sobre el uso/crítica simbólica, mientras que, constitucional (arts. 4 y $20.2 \mathrm{CE})^{48}$ y jurisprudencialmente, los límites se omiten o se plantean como excepcionales. El valor del pluralismo político del art. 1.1 CE y, en general, los derechos políticos contenidos en el texto constitucional juegan a favor de una interpretación favorable al uso de los símbolos constitucionales, legales o incluso alegales, así como de una crítica (incluso poco mesurada) a los mismos. Mientras, la protección a lo que los símbolos representan se ha desdibujado por un deficitario planteamiento de la cuestión, y un dudoso estiramiento de tipos penales pensados para otras finalidades o surgidos en otros contextos históricos, que decaen por completo ante la fortaleza protectora que se deriva de los derechos y libertades ejercitados por quienes los usan o critican. El resultado es que se corre el riesgo, por ello, de

48 Art. 20.2 CE: «El ejercicio de estos derechos no puede restringirse mediante ningún tipo de censura previa. [...]. 4. Estas libertades tienen su límite en el respeto a los derechos reconocidos en este Título, en los preceptos de las leyes que lo desarrollen y, especialmente, en el derecho al honor, a la intimidad, a la propia imagen y a la protección de la juventud y de la infancia. [...]». 
olvidar que también hay un problema de desamparo jurídico sobre las facetas de principios y derechos (ya se han aludido: dignidad, desarrollo de la personalidad, integridad moral, pensamiento, honor, etc.) de personas y grupos afectados por los usos o críticas a la simbología que los refleja.

Los símbolos han de servir para unir en torno a una idea, pero si así no fuera, no deberían pasar a representar objeto de conflicto, y menos, como se plantea en este estudio, cuando su doble naturaleza (reflejo de España, de su nación y de sus nacionales, pero también mecanismo de materialización de derechos y libertades a través de la expresión) ha de interesar al Estado al momento de establecer su estatuto protector. El sistema carece de posibilidades para acompasar su actuación de promoción o protección sobre los mismos a los sentimientos que cada ciudadano tenga al verse reconocido en ellos, o a rechazarlos públicamente. A la organización política y administrativa le compete materializar nuestros derechos ciudadanos, y solo en la medida en que estos se transgreden con el uso o la crítica de determinados símbolos, adquiere importancia la respuesta del Estado. A la vista de lo relatado en este estudio, la Constitución carece de elementos para imponer objetivamente un respeto a sus símbolos, pero sí tiene la capacidad de responder para proteger los valores y derechos civiles y políticos que amparan pensamientos, situaciones y hasta sentimientos de cada persona, componentes ineludibles de los primeros (de la dignidad, del honor, de la opción política, etc.). El régimen jurídico de los símbolos constitucionales, según he intentado justificar, debe conectarse de manera directa con la protección de los derechos y libertades concernidos en su uso o crítica, sin que sea posible una exacerbación de los contenidos que proyectan por sí mismos, aludiendo a circunstancias históricas, ambientales, políticas o de cualquier otra índole. La afrenta a los símbolos nacionales en la medida que afecte a derechos concretos de cada persona que habita en un Estado genera la justificación para ciertas sanciones a los ofensores. La burla, el menoscabo o cualquier tipo de ataque «simbólico» hacia el «símbolo», como manifestación extrema pero admisible de las libertades de pensamiento, expresión y del pluralismo político, debería asumir un castigo derivado de la falta de respeto, pero precisamente su condición de deleznable ${ }^{49}$ debería animar al aparato coercitivo del Estado democrático a distanciarse de la aplicación de onerosas consecuencias punitivas, aunque pueda barajar otras de naturaleza menor y

49 En sus dos primeras acepciones, según el diccionario de la RAE, al menos se corresponde con la futilidad de la mayor parte de agravios simbólicos: 1. adj. Despreciable, de poco valor. 2. adj. Poco durable, inconsistente, de poca resistencia. 3. adj. Que se rompe, disgrega o deshace fácilmente. 4. adj. Que se desliza y resbala con mucha facilidad. 
pasajera para evidenciar el distanciamiento de los ofensores con el compromiso colectivo de buena convivencia y con la afectación, indirecta y difícil de probar, de derechos y libertades ajenas. Son tan necesarias las consecuencias jurídicas ante la afrenta a lo que reflejan los símbolos como que la ponderación de los hechos (naturaleza de los símbolos como mero objeto, e imposibilidad de determinar el daño sentimental derivado, eso sí, de valores y derechos de la persona) impida una respuesta jurídico-punitiva desproporcionada.

\section{EL USO DE LOS SÍMBOLOS POR LOS RESPONSABLES INSTITUCIONALES. DE LA AFRENTA A LOS SÍMBOLOS CONSTITUCIONALES A LA PROMOCIÓN DE SIMBOLOGÍA ALTERNATIVA. REMISIÓN}

Para finalizar una aproximación al tema de la protección de símbolos, sería necesario aludir a su utilización por parte de los responsables gubernamentales, territoriales y administrativos, lo que presenta el tema en un plano absolutamente distinto del que hasta ahora se ha tratado, respecto del uso/crítica por parte de personas y grupos de personas en el ejercicio de sus derechos. Las normas ordenan el uso de un símbolo en un edificio público y en virtud de la sujeción a la legalidad vigente, los responsables institucionales cumplen con su deber y materializan la objetividad y neutralidad exigible a las Administraciones (STS 184/2016, de 28 de abril). Pero los problemas de aplicación de esta sencilla regla derivan de los episodios socialmente descritos como "guerra de las banderas», que tiene varias formas de presentarse, desde el uso expansivo y reivindicativo fuera de la comunidad (STC 94/1985, de 29 de julio), hasta la retirada de banderas constitucionales y su sustitución por simbología alternativa (entre decenas de la jurisdicción ordinaria, Sentencia del Juzgado de lo Contencioso-Administrativo núm. 2 de Barcelona 242/2016, de 22 de julio), pasando por la simple omisión de uso (SSTS 2617/1988, de 14 de abril, 5429/2007, de 24 de julio, o 2403/2016, de 7 de junio), el recuerdo de banderas históricas (Juzgado de lo Contencioso Administrativo núm. 8 de Valencia, de 2 de febrero de 2018), o la ejecución fraudulenta del imperativo constitucional de colocación de banderas (STS 7725/2011, de 17 de noviembre $)^{50}$. Lo común de todos estos supuestos es la búsqueda de subterfugios jurídicos y metajurídicos para burlar tanto la claridad de la ley como la contundencia jurisprudencial que se advierte en la exigencia del uso en

50 Más ejemplos y casos de ejecuciones fraudulentas del imperativo de colocar banderas en Troncoso, 2018: 45. 
edificios oficiales, que es indudable incluso por encima de la pasividad pública o social en reclamarla, que ha permitido en algunas instituciones largos períodos de omisión práctica de este deber ${ }^{51}$. La proyección del asunto es socialmente mucho más compleja y nos remitimos a posteriores estudios sobre la materia, para solo concluir aquí con un recordatorio de la debida neutralidad de los responsables públicos en el cumplimiento de las obligaciones legales.

\section{Bibliografía}

Aguilera, C. y Vernet, J. (1993). Cuestiones simbólicas y Constitución española. Revista de Estudios Políticos, 79, 139-160.

Alegre, E. (coord.) (2008). El himno como símbolo politico. León: Universidad de León.

Alzaga, O. (2016). Comentario sistemático a la Constitución española de 1978. Madrid: Marcial Pons.

Belda, E. (2003). El Poder del Rey. Alcance constitucional efectivo de las atribuciones de la Corona. Madrid: Senado.

- (2015). ¿Qué le falta a la monarquía española para estar plenamente racionalizada? La monarquia española del Siglo XXI. Valladolid: Fundación Aranzadi Lex Nova; Thomson Reuters.

Brage, J. (2008). El himno como símbolo del Estado: dimensión jurídico-política. En M. Á. Alegre (coord.). El himno como simbolo político (pp. 23-45). León: Universidad de León.

Fernández-Sarasola, I. (2019). Libertad de expresión y tutela de la Corona: el caso de «El Jueves». Teoría y Realidad Constitucional, 43, 371-387. Disponible en: https://doi. org/10.5944/trc.43.2019.24430.

García Pelayo, M. (1991 [1964]). Ensayo de una teoría de los símbolos políticos. En M. García Pelayo. Obras completas (pp. 987-1031). Madrid: Centro de Estudios Constitucionales.

Gutiérrez, C. (2018). Juramento o promesa y lealtad a la Constitución. En B. Pendás (dir.). España Constitucional (1978-2018). Trayectoria y perspectivas (pp. 1951-1969). Madrid: Centro de Estudios Constitucionales.

Häberle, P. (1987). Feiertagsgarantien als Kulturelle Identitätselemente des Verfassungsstaates. Berlin: Duncker und Humblot. Disponible en: https://doi.org/10.3790/978-3-428-06332-1.

- (2012). El Himno nacional como elemento de identidad cultural del Estado Constitucional. Madrid: Dykinson.

López Ulla, J. M. (2017) Libertad de expresión y discurso del odio. Fragmentum, 50, 139161. Disponible en: https://doi.org/10.5902/2179219428863.

Martin Herrera, D. (2018). Hate Speech y libertad de expresión desde la Grecia de Sócrates a la democracia actual. e-SLegal History Review, 28. Disponible en: https://doi.org/10.2307/j. ctv6gqxfp.

51 El caso de la omisión de la bandera nacional durante lustros en una academia de policía autonómica, reflejado en la STS 5429/2007, de 24 de julio. 
Mendizábal, R. de (2000). La Constitución como símbolo y los símbolos en la Constitución. Actualidad Administrativa, 43, 1197-1205.

Mikunda, E. (2008). Los himnos en particular: panorama europeo global en perspectiva cultural comparada. En M. Á. Alegre (coord.). El himno como símbolo político (pp. 23-45). León: Universidad de León.

Moreno, J. y Núńez, X. M. (2018). Los símbolos nacionales en la España Constitucional (19782017): Un consenso precario. En B. Pendás (dir.). España Constitucional (1978-2018). Trayectoria y perspectivas (pp. 381-394). Madrid: Centro de Estudios Constitucionales.

Presno, M. A. (2018). Crónica de una condena anunciada: el asunto Stern Taulats y Roura Capellera C. España sobre la quema de fotos del Rey. Teoría y Realidad Constitucional, 42, 539-549. Disponible en: https://doi.org/10.5944/trc.42.2018.23644.

Queralt, J. J. (2013). Delitos contra la Corona: apuntes sobre descoordinación normativa y paradojas penales. En J. G. Fernández Teruelo et al. (coords.). Estudios penales en homenaje al profesor Suárez Montes (pp. 535-546). Oviedo: Constitutio Criminalis Carolina.

Ridao, J. (2019). La libertad de expresión y sus conflictos en el espacio público. Manifestaciones, escraches y simbolos politicos. Cizur Menor (Navarra): Thomson Reuters Aranzadi.

Rollnert, G. (2019a). El Rey, símbolo de la unidad y permanencia del Estado. En A. Villanueva (dir.). 40 años de Monarquía Parlamentaria (pp. 11-36). A Coruña: Colex. (2019b). El discurso del odio: una lectura crítica de la regulación internacional. Revista Española de Derecho Constitucional, 115, 81-109.

Sánchez de Diego, M. (2011). Las injurias al Rey a la luz de la jurisprudencia del TEDH. Sentencia del TEDH Otegi Mondragón contra España (Requête núm. 2034/07), de 15 de marzo 2011. Revista General de Derecho Europeo, 24.

Smend, R. (1985). Constitución y Derecho Constitucional. Madrid: Centro de Estudios Constitucionales.

- (1994). Staatsrechtliche Abhandlungen und andere Aufsätze. Berlin: Duncker und Humblot.

Solozábal, J. J. (2008). Artículo 4. En M. E. Casas y M. Rodríguez-Piñero (dirs.). Comentarios a la Constitución española (pp. 74 a 79). Madrid: Fundación Wolters Kluwer.

Tajadura, J. (2001). Estudio preliminar. En A. Torres del Moral y J. Tajadura Tejada (dirs.). Los preámbulos constitucionales en Iberoamérica (pp. 13-36). Madrid: Centro de Estudios Constitucionales.

Teruel, G. M. (2018a). Internet, incitación al terrorismo y libertad de expresión en el marco europeo. InDret, 3, 13-20.

(2018b). Cuando las palabras generan odio: límites a la libertad de expresión en el ordenamiento constitucional español. Revista Española de Derecho Constitucional, $114,13-45$.

Troncoso, A. (2018). La bandera y la capitalidad. Revista de Derecho Politico, 103, 29-76. Disponible en: https://doi.org/10.5944/rdp.103.2018.23197.

Vázquez-Portomeñe, F. (2002). Algunas consideraciones sobre la naturaleza jurídica del delito de ultrajes a la bandera. Estudios Penales y Criminológicos, 23, 216-252.

Vernet, J. (2003). Símbolos y fiestas nacionales en España. Teoría y Realidad Constitucional, 12-13, 99-122. Disponible en: https://doi.org/10.5944/trc.12-13.2003.6623. 